\title{
İZOBÜTAN DEHİDROJENASYONU İÇİN REAKSİYON MEKANİZMASININ ARAŞTIRILMASI
}

\author{
Saliha ÇETINNYOKUŞ KILIÇARSLAN \\ T.C. Başbakanlık Afet ve Acil Durum Yönetimi Başkanlı̆̆ı, Planlama ve Zarar Azaltma Dairesi, 06530, \\ Çukurambar, Ankara \\ $\underline{\text { s.saliha@gmail.com, saliha.cetinyokus@afad.gov.tr }}$
}

(Geliş/Received: 16.09.2015; Kabul/Accepted: 27.01.2016)

ÖZET

Bu çalışmada, Cr/MCM-41 katalizörü üzerinde izobütan dehidrojenasyonu için reaksiyon mekanizmasının belirlenmesi amaçlanmıştır. Mekanizma çalışmalarına başlamadan önce deneysel reaksiyon hızlarının konsantrasyon ile değişimi değerlendirilmiş ve yüzey reaksiyonu kontrolünün önemli olduğu belirlenmiştir. Deneysel olarak belirlenen reaksiyon kinetik üssünün 1-2 arasında değişim göstermesi yüzey reaksiyonunun mono veya bimoleküler olabileceğini düşündürmüş, bu nedenle çok sayıda mekanizma çalışması arasından yüzey reaksiyon kontrollü (Model I\&Model II) basit reaksiyon mekanizmaları üzerinde çalışılmıştır. Üs kuralına dayanan, çeşitli parametrelerin indirgenmesi ile elde edilen denklemler üzerinden de model (Model III) çalışması yürütülmüsşür. Model çalışmalarına ait parametrelerin tahmininde SPSS 17,0 (Windows Evaluation Version) programından yararlanılmış doğrusal olmayan regresyon analizleri yapılmıştır. Model sonuçları ile deneysel reaksiyon hızı değerleri arasındaki en iyi uyum, bimoleküler yüzey reaksiyon kontrollü mekanizmada (Model I) belirlenmiştir. Reaksiyon için tahmin edilen aktivasyon enerjisi (49-55 kJ/mol) ve adsorpsiyon denge sabiti (1-3) parametre değerleri literatür ile uyumlu bulunmuştur.

Anahtar Kelimeler: İzobütan dehidrojenasyonu, Cr/MCM-41, reaksiyon mekanizması, SPSS

\section{REACTION MECHANISM RESEARCH FOR ISOBUTANE DEHYDROGENATION}

\begin{abstract}
In this study, determination of the reaction mechanism on $\mathrm{Cr} / \mathrm{MCM}-41$ catalyst for isobutane dehydrogenation was aimed. The change of experimental reaction rate values with concentration was evaluated before the beginning of the mechanism studies and it was determined that it was important to control surface reactions. The reaction order (n) obtained by experimantally for isobutane dehydrogenation showing exchanges between 1-2 indicated that surface reactions would be mono or bimolecular, so surface reaction controlled basic reaction mechanisms (Model I\&Model II) were studied among many mechanism studies. On the equations obtained by reduction of various parameters (Model III) based on the rule of order were also studied. Nonlinear regression analysis were carried out to estimate the parameters of the model studies utilizing the SPSS 17.0 program (Windows Evaluation Version). The best agreement with the experimental reaction rate values was determined on the bimolecular surface reaction controlled mechanism (Model I). Parameter values of activation energy (49$55 \mathrm{kj} / \mathrm{mol}$ ) and the adsorpsion equilibrium constants (1-3) estimated for isobutane dehyrogenation reaction were consistent with the literature.
\end{abstract}

Keywords: Isobutane dehydrogenation, $\mathrm{Cr} / \mathrm{MCM}-41$, reaction mechanism, SPSS

\section{GİRIŞ (INTRODUCTION)}

İzobütan dehidrojenasyonu, endüstriyel öneme sahip bir reaksiyondur. Reaksiyon ürünü izobüten, metil tersiyel bütil eter (MTBE), sentetik kauçuk ve diğer organik ürünlerin üretiminde kullanılan önemli bir hammaddedir. Reaksiyon için farklı katalizör, reaktör tipi ve rejenerasyon sistemi kullanan ticari prosesler vardır [1]. İzobütan dehidrojenasyonu için temelde $\mathrm{Cr}$ ve $\mathrm{Pt}$ bileşenli olmak üzere iki tip katalizör geliştirilmesi üzerinde durulduğu tespit edilmiştir. Düşük maliyet yönü ile $\mathrm{Cr}$ temelli katalizörler üzerinde seçicilik, aktivite ve kararlılığı artıracak yöndeki çalışmaların son dönemde önem kazandığı 
görülmektedir [2-5]. Heterojen kataliz mekanizmaları karmaşıktır. Olası hız belirleyici basamak, reaktantın katalizöre taşınımına, reaktant adsorpsiyonuna, reaktant yüzey difüzyonuna, kendine özgü reaksiyonlara ve ikincil reaksiyonlara, ürün yüzey difüzyonuna, katalizörden ürün taşınımına, katalizör deaktivasyonuna ve katalizör yeniden yapılanmasına bağlı değişim göstermektedir. Endotermik ve termodinamik denge limitasyonlu izobütan dehidrojenasyonu için kinetik ve reaksiyon mekanizması çalışmaları ilk olarak krom-alüminyum katalizörleri üzerinde gerçekleştirilmiştir [6]. Kinetik eşitlikler Langmuir-Hinshelwood üzerinden geliştirilmiş ve deneysel veriler ile uyum elde edilmiştir. Hız belirleyen basamak, yüzey reaksiyonu ve izobütan adsorpsiyonu olarak belirlenmiştir [6]. Katalitik kinetiğin doğru olarak belirlenmesi, ikincil reaksiyonlar, sıcaklık salınımları, aktif sitelere erişebilirlik, difüzyon limitasyonları ve kok oluşumuna bağlı katalizör deaktivasyonu gibi etkileri minimize etmektedir. Minh ve Brown tarafindan yürütülen çalışmada, HZSM-5 $(33,0)$, HZSM-5 $(94,2)$, demir ve mordenit üzerinde izobütanın dehidrojenasyonu ve parçalanması için kinetik parametreler belirlenmiştir. Görünür aktivasyon enerjisi izobütan dehidrojenasyonu için HZSM-5 $(33,0)$, HZSM-5 $(94,2)$, demir üzerinde $136 \pm 6 \mathrm{~kJ} / \mathrm{mol}$; mordenit üzerinde $95 \pm 5 \mathrm{~kJ} / \mathrm{mol}$ olarak elde edilmiştir. Hız belirleyici basamakta gözlenen farklılık, desorpsiyon ve reaksiyondaki değişiklikle açıklanmıştır [7]. Yanping ve Brown tarafindan HZSM-5 üzerinde aynı reaksiyonların kinetiği incelenmiştir. Elde edilen yüksek eksponansiyel faktörler, izobütanın adsorpsiyonu için korumalı aktif sitelerin korunmasız aktif sitelerden daha az etkili olması ile açıklanmıștır. Belirlenen aktivasyon enerjileri teori ile uyumlu bulunmuştur [8]. Milas ve Nascimento ise aynı reaksiyonları ZSM-5 zeoliti üzerinde incelemiștir. Her iki reaksiyonda da $\mathrm{C}-\mathrm{H}$ ve C-C bağları yerine doğrudan yüzey aktif maddenin karbon atomuna atak yaptığı, daha gerideki aktif sitelerin parçalanma reaksiyonu üzerinden dehidrojenasyon reaksiyonunu meydana getirdiği tespit edilmiştir [9]. Sanchez-Castillo ve arkadaşları, H-mordenit ve $\beta$-zeolit üzerinde izobütan dönüşümü için reaksiyon kinetik verisi toplamıştır. Beslemeye izobüten ilavesinin katalizör performansını artırdığ tespit edilmiştir [10]. Bijani ve Sahebdelfar çalışmalarında, izobütan dehidrojenasyonu için birinci mertebe bağımlılığı dikkate alan kimyasal denge limitasyonuna dayanan kinetik ifadeyi kullanmıștır [11]. Rahsidi ve arkadaşları, ticari Pt-Sn-K/ $/ \mathrm{Al}_{2} \mathrm{O}_{3}$ katalizörü üzerinde propan ve izobütan dehidrojenasyonunun kinetiğini incelemiştir. Model, propan, hidrojen ve izobütanın aynı aktif sitede adsorplandığ1 düşünülerek türetilmiş, model sonucu deney sonucu ile uyumlu bulunmuştur [12]. Vernikouskaya ve arkadaşları tarafindan $\mathrm{Cr}_{2} \mathrm{O}_{3} / \mathrm{Al}_{2} \mathrm{O}_{3}$ katalizörü üzerinde propan-izobütan karışımı için yürütülen model çalışmasında, dehidrojenasyon, parçalanma ve kok oluşum reaksiyon hızlarını içeren kinetik eşitlik kullanılmıştır [13]. Miracca ve Piavesan, model çalışmasında benzer şekilde aromatikleşme reaksiyonunu da dikkate alan hız ifadesini kullanmıștır [14]. Yürütülen çalıșmada, hidrotermal olarak sentezlenmiş $\mathrm{Cr} / \mathrm{MCM}-41$ (kütlece $\% 3$ Cr) katalizörleri [15] üzerinde izobütan dehidrojenasyonu için reaksiyon mekanizması geliştirilmiştir. Mekanizma çalışılırken üç farklı model çalışması (Model I-III) yürütülmüştür. Regresyon analizi ile parametre tahmininde SPSS 17.0 programı kullanılmıştır. Model sonuçları, deneysel hız değerleri ile karşılaştırılmış, katalizör üzerinde en uygun mekanizma belirlenmeye çalışılmıştır.

\section{REAKSIYYON KINETİĞININ MODELLENMESI (MODELLING OF REACTION KINETICS)}

Cr bileșenli farklı destekli katalizörler üzerinde literatür araştırmasında bahsedildiği gibi izobütan dehidrojenasyonu için hiz ifadesinin belirlendiği, ancak Cr/MCM-41 katalizörü üzerinde böyle bir çalışmanın yürütülmediği tespit edilmiştir. $\mathrm{Bu}$ nedenle, reaksiyon mekanizması ile belirlenecek hız değerlerinin karşılaştırılmasında deneysel reaksiyon hızı değerlerinden yararlanılmıştır. Silika ile dönüşümlü metal tuz ilaveli mekanizma ile hidrotermal olarak sentezlenmiş \%100 izobüten seçiciliğine sahip Cr/MCM-41 (\%3 Cr) katalizörü (yüzey alanı: $990 \mathrm{~m}^{2} / \mathrm{g}$; ortalama gözenek çapı: $2 \mathrm{~nm}$; duvar kalınlığı: $1,4 \mathrm{~nm}$ ) üzerinde deneysel çalışmalar yürütülmüştür. Deney sistemi, yatay bir tüp firın içine yerleştirilmiş kuvars cam reaktörden $(\mathrm{ID}=0,65 \mathrm{~cm}$, $\mathrm{L}=100 \mathrm{~cm}$ ) oluşmaktadır. Cam reaktörün ortasına gözenekli bir cam elek yerleştirilmiştir. Deney sisteminde, diferansiyel reaktör kabulünün yapıldığı dolgulu kolon-sürekli akış reaktörde sabit katalizör miktarı üzerinden $(0,05 \mathrm{~g})$ farklı izobütan başlangıç konsantrasyonlarında $\quad\left(\mathrm{C}_{\mathrm{A} 0}=0,002 \mathrm{~mol} / \mathrm{L} ; \quad 0,006\right.$ $\mathrm{mol} / \mathrm{L} ; \quad 0,009 \mathrm{~mol} / \mathrm{L} ; 0,0118 \mathrm{~mol} / \mathrm{L})$ ve farklı sicaklıklarda $(723 \mathrm{~K}, 773 \mathrm{~K}, 823 \mathrm{~K}, 873 \mathrm{~K})$ deneysel çalışmalar yürütülmüştür. Helyum ve izobütandan oluşan gaz karışımı besleme akımı olarak kullanılmış ve atmosferik basınçta çalışılmıştır. Her bir sıcaklık için konsantrasyona bağlı dört ayrı veri seti oluşturulmuş, her bir sıcaklıkta yürütülen çalışmalarda taze katalizör kullanılmıştır. Yatışkın hal şartlarında (15. dakika) reaktör çıkışından alınan gaz numuneleri silika kolon ve TCD dedektörü ihtiva eden gaz kromatografi (GC-SRI 8610C) cihazında analiz edilmiştir. Diferansiyel reaktör şartlarının sağlanması için düşük izobütan dönüşümlerinin olduğu $(<\% 1)$, çok küçük temas sürelerinde çalışılmıştır. Görünür reaksiyon hızı $\left(\mathrm{R}_{\mathrm{A}}{ }^{*}, \mathrm{~mol} / \mathrm{g}_{\mathrm{kat}} . \mathrm{s}\right)$ eşitlik (1) ile hesaplanmıştır.

$$
-R^{*}=\frac{x_{A f} \cdot F_{A 0}}{V \cdot\left(1-\varepsilon_{b}\right) \cdot \rho_{k a t}}
$$

Mekanizma çalışmalarına başlamadan önce, farklı sicaklıklarda belirlenen görünür reaksiyon h1z1 değerlerinin izobütan başlangıç konsantrasyonu $\left(\mathrm{C}_{\mathrm{A} 0}\right)$ ile değişimi incelenmiştir (Şekil 1). 


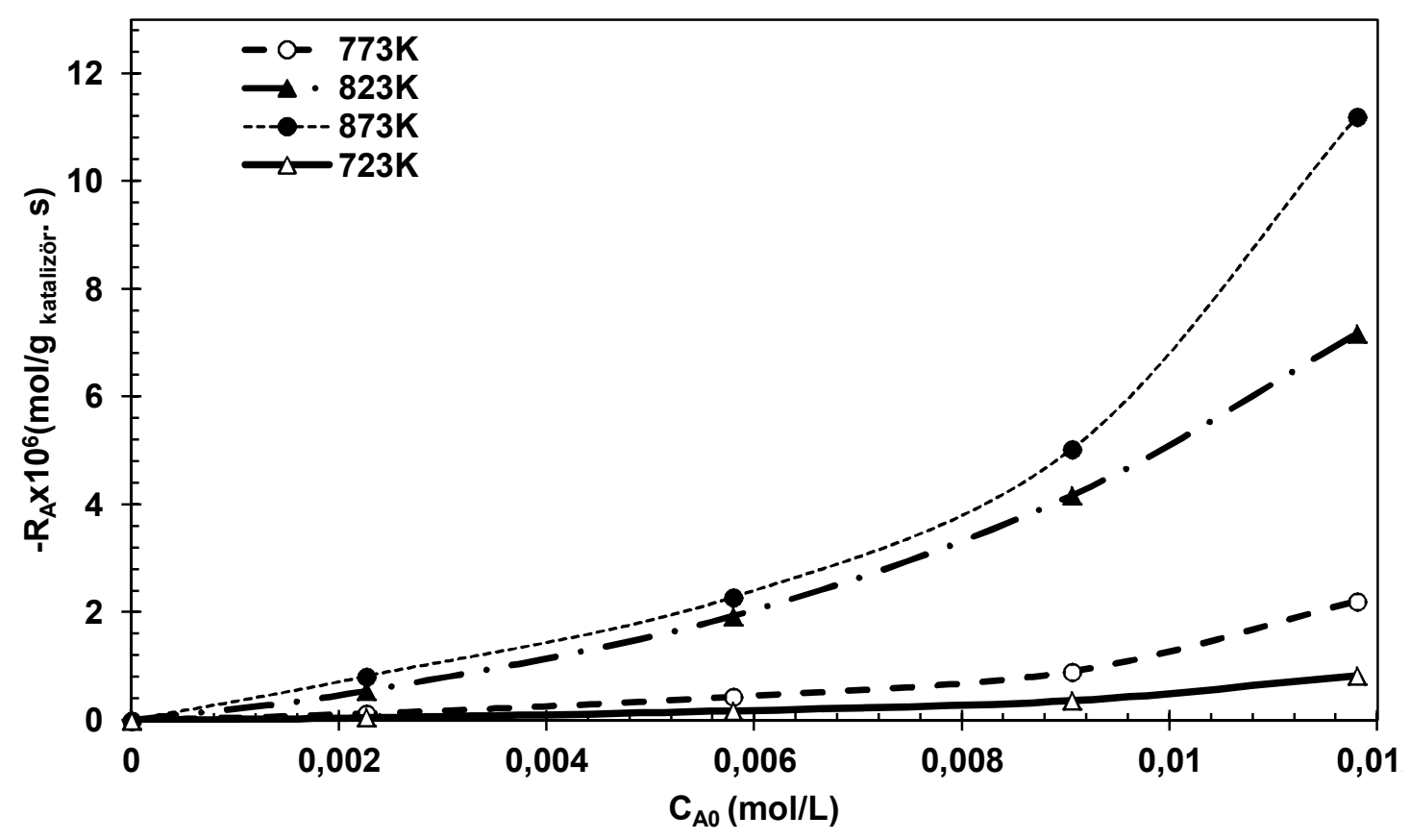

Şekil 1. Görünür reaksiyon hızı değerlerinin izobütan başlangıç konsantrasyonu ile değişimi (Variation of apparent reaction rate values with initial isobutane concentration)

Şekil 1' deki görünür reaksiyon hızı değerleri ve izobütan başlangıç konsantrasyonu verilerinden yararlanılarak her bir sıcaklıkta kinetik üs belirlenmiş, izobütan dehidrojenasyonu reaksiyonu için tüm sıcaklıklarda kinetik üs (n) 1-2 arasinda tespit edilmiştir. Hız değerlerinin konsantrasyonla artması, reaksiyon için adsorpsiyon basamağının önemli olmadığını göstermiştir. Reaksiyon için adsorpsiyonun önemli olması durumunda, önce daha küçük eğimde reaksiyon hızlarının yavaş bir şekilde artması, adsorpsiyon dengesine ulaşıldığında reaksiyon hızının bir süre sabitlenmesi ve sonrasında adsorplanmış katalizör yüzeyinin kademeli olarak serbest kalmasına bağlı olarak reaksiyon hızının azalış göstermesi şeklinde bir değişim olması gerekmektedir $[16,17]$. Katalizör üzerinde izobütan dehidrojenasyon reaksiyonu için izobütan adsorpsiyonunun hızlı bir şekilde gerçekleştiği öngörülerek çok sayıda reaksiyon mekanizması arasından yüzey reaksiyonun kontrolünü öne çıkaran basit mekanizmalar (Model I \& Model II) üzerinde çalışılmasına karar verilmiştir. Ayrıca, reaksiyon için üst yasası model yaklaşımı (Model III) ile çalışmalar yürütülmüştür.

\subsection{Model I (Model I)}

Reaksiyon kinetik üs değerinin 1-2 arasında değişim göstermesi, reaksiyonun mono veya bimoleküler olabileceğini düşündürmüştür. Aşağıdaki şekilde bimoleküler yüzey reaksiyonu basamağını içeren bir mekanizma (Eş. 2-5) önerilmiştir:

$$
A+S \stackrel{K_{1}}{\rightleftarrows} A S
$$

$$
\begin{gathered}
A S+A S \underset{k_{2}}{\stackrel{k_{1}}{\rightleftarrows}} B S+C S \\
\quad K_{2} \\
B S \stackrel{K_{3}}{\rightleftarrows} B+S \\
C S \stackrel{K_{3}}{\rightleftarrows} C+S
\end{gathered}
$$

Bu mekanizmada, $K_{l}(\mathrm{~L} / \mathrm{mol})$ izobütan adsorpsiyon denge sabitini, $K_{2}(\mathrm{~mol} / \mathrm{L})$ ve $K_{3}(\mathrm{~mol} / \mathrm{L})$ sirasiyla izobüten ve hidrojen desorpsiyon denge sabitini ifade etmektedir. $K_{I}\left(\mathrm{~L}^{2} / \mathrm{mol} . \mathrm{g}_{\text {kat. }} . \mathrm{s}\right)$ ileri yönde reaksiyon hız sabiti, $k_{2}\left(\mathrm{~L}^{2} / \mathrm{mol}_{\mathrm{g}} \mathrm{g}_{\text {katalizör. }} \mathrm{s}\right)$ geri yönde reaksiyon hız sabitidir. $S$ adsorplanan yüzey konsantrasyonunu (mol/L), $A, B$ ve $C$ sirasiyla izobütan, izobüten ve hidrojen konsantrasyonlarını (mol/L) temsil etmektedir. Yüzey reaksiyonunun dengede olduğu ve reaksiyonu kontrol ettiği kabul edildiğinde aşağıdaki hız eşitliği (Eş. 6) elde edilmiştir.

$$
-R_{A}=\frac{C_{S 0}^{2}}{\left(1+K_{1} C_{A}+\frac{C_{B}}{K_{2}}+\frac{C_{C}}{K_{3}}\right)^{2}} \cdot\left(K_{1}^{2} k_{1} C_{A}^{2}-\frac{k_{2} C_{B} C_{C}}{K_{2} K_{3}}\right)
$$

Diferansiyel reaktörde yürütülen kinetik çalışmalarda dönüşümler çok küçük $\left(\mathrm{x}_{\mathrm{A}}<\% 1\right)$ olduğundan ürün konsantrasyonları da küçük değerlerde $\left(2,9 \times 10^{-6}-\right.$ $3,37 \times 10^{-4} \mathrm{~mol} / \mathrm{L}$ ) belirlenmiştir. Ürün izobüten ve hidrojen konsantrasyonlarının çok küçük olduğu 
varsayımları ilgili kısaltmalar yapıldığında Eş. 7’ de görülen hız ifadesi elde edilmiştir.

$$
-R_{A}=k_{x} \cdot \frac{K_{1}^{2} \cdot C_{A}^{2}}{\left(1+K_{1} \cdot C_{A}\right)^{2}} ; k_{x}=k_{1} \cdot C_{S 0}^{2}
$$

Eşitlik 7 , de $-R_{A}$, reaksiyon hızı (mol $\left./ \mathrm{g}_{\text {kat. }} . \mathrm{s}\right) ; C_{A}$, izobütan konsantrasyonu $(\mathrm{mol} / \mathrm{L}), \quad C_{S 0}, \quad$ toplam adsorplanan yüzey konsantrasyonunu (mol/L) simgelemektedir. Doğrusal olmayan (Non-lineer) regresyon analizi ile her bir sıcaklık için adsorpsiyon denge sabiti $\left(K_{l} ; \mathrm{L} / \mathrm{mol}\right)$ ve reaksiyon hiz sabiti $\left(k_{x}\right.$; $\left.\mathrm{mol} / \mathrm{g}_{\text {kat. }} . \mathrm{s}\right)$ değerleri belirlenmiştir. Regresyon analizi için SPSS 17.0 (Windows Evaluation Version) programı kullanılmıştır.

\subsection{Model II (Model II)}

Model I' de gösterimi verilen reaksiyonlardan, yüzey reaksiyonunun dengede ve monomoleküler olduğu düşünülerek aşağıdaki hız eşitliği (Eş. 8) elde edilmiştir.

$$
-R_{A}=\frac{k_{1} K_{1} C_{A} C_{S 0}}{\left(1+K_{1} C_{A}+\frac{C_{B}}{K_{2}}+\frac{C_{C}}{K_{3}}\right)}
$$

$$
-\frac{k_{2} C_{B} C_{C}}{K_{2} K_{3}} \cdot\left(\frac{C_{S 0}}{\left(1+K_{1} C_{A}+\frac{C_{B}}{K_{2}}+\frac{C_{C}}{K_{3}}\right)}\right)^{2}
$$

Aynı varsayımlar ile yapılan kısaltmalar sonucunda eşitlik aşağıdaki forma indirgenmiştir.

$$
-R_{A}=k_{z} \cdot \frac{K_{1} \cdot C_{A}}{\left(1+K_{1} \cdot C_{A}\right)} ; k_{z}=k_{1} \cdot C_{S 0}
$$

Doğrusal olmayan regresyon analizi ile her bir sicaklık için adsorpsiyon denge sabiti $\left(K_{l} ; \mathrm{L} / \mathrm{mol}\right)$ ve hız sabiti $\left(k_{z} ; \mathrm{L} / \mathrm{g}_{\text {kat. }} . \mathrm{s}\right)$ değerleri belirlenmiştir.

\subsection{Model III (Model III)}

Üst yasası model yaklaşımından faydalanılmıştır. Üst yasası modeli aşağıdaki eşitlikte (Eş. 10) verilmiştir.

$$
-R_{A}=k_{1} C_{C_{4} H_{10}}^{\alpha}-k_{2} \cdot C_{C_{4} H_{8}}^{\beta} \cdot C_{H_{2}}^{\gamma}
$$

$k_{1}\left(\mathrm{~L}^{\alpha} \cdot \mathrm{mol}^{1-\alpha} / \mathrm{g}_{\text {kat. }} \mathrm{s}\right)$ ve $k_{2}\left(\mathrm{~L}^{\beta+\gamma} \cdot \mathrm{mol}^{1-(\beta+\gamma)} / \mathrm{g}_{\text {kat. }} \mathrm{s}\right)$ siras1 ile ileri ve geri yöndeki reaksiyon hız sabitleri; $\alpha, \beta, \gamma$ reaksiyon mertebeleridir. Model eşitliğinde farklı parametreler indirgenerek beş farklı model çalışması yürütülmüştür. Tablo 1' de incelenen üs yasası modelleri verilmiştir.

Tablo 1. Üs yasası modelleri (Model III) (Power law models (Model III))

\begin{tabular}{|l|l|l|}
\hline No & \multicolumn{1}{|c|}{ Model } & \multicolumn{1}{c|}{ Parametreler } \\
\hline i & Eş. 14 & $k_{1}, k_{2}, \alpha, \beta, \gamma$ \\
ii & Eş. 14, indirgenmiş & $k_{1}, k_{2}, \alpha$ \\
iii & Eş. 14, indirgenmiş & $k_{1}, k_{2}, \beta$ \\
iv & Eş. 14, indirgenmiş & $k_{1}, k_{2}, \gamma$ \\
v & Eş. 14, indirgenmiş & $k_{1}, k_{2}$ \\
\hline
\end{tabular}

İndirgenen üslerin yerini birim bir almıştır ve üsler birden farklı bir sayı değerine sahip olarak kabul edilmiştir. Hız sabiti $k_{i}$ Arrhenius eşitliğine göre değişim göstermektedir. Model i-v çalışması SPSS programı kullanılarak iki uç sıcaklık değeri olan $723 \mathrm{~K}$ ve $873 \mathrm{~K}$ sıcaklıklar için çalışılmıştır.

\section{PARAMETRE TAHMINI (PARAMETER ESTIMATION)}

Doğrusal olmayan (Non-lineer) regresyon analizi ile her bir sıcaklık için adsorpsiyon denge sabiti $\left(K_{l}\right)$ ve reaksiyon hız sabiti $\left(k_{x} ; k_{z}\right)$ değerleri belirlenmiştir. Farklı sıcaklıklarda Model I ve Model II yaklaşımı ile belirlenen parametre değerleri Tablo 2' de verilmiştir.

Tablo 2' den sicaklık arttıkça adsorpsiyon denge sabiti ve reaksiyon hız sabiti değerlerinin her iki model yaklaşımı için artış gösterdiği görülmektedir.

Tablo 2. Model I ve Model II yaklaşımı ile farklı sıcaklıklarda belirlenen parametrelerin $\left(K_{l}, k_{x}, k_{z}\right)$ değerleri (Determined parameters $\left(K_{l}, k_{x}, k_{z}\right)$ values with Model I and Model II approach at different temperatures)

\begin{tabular}{|c|c|c|c|c|}
\hline \multirow{2}{*}{ Sicaklık(K) } & \multicolumn{2}{|c|}{ Model I } & \multicolumn{2}{c|}{ Model II } \\
\cline { 2 - 5 } & $K_{1}(\mathrm{~L} / \mathrm{mol})$ & $k_{x}\left(\mathrm{~mol} / \mathrm{g}_{\text {kat. }} . \mathrm{s}\right)$ & $K_{1}(\mathrm{~L} / \mathrm{mol})$ & $k_{z}\left(\mathrm{~L} / \mathrm{g}_{\text {kat.. }} \mathrm{s}\right)$ \\
\hline 723 & 0,744 & 0,011 & 0,824 & 0,001 \\
773 & 0,810 & 0,023 & 1,246 & 0,002 \\
823 & 1,258 & 0,034 & 1,530 & 0,004 \\
873 & 1,298 & 0,046 & 2,717 & 0,005 \\
\hline
\end{tabular}

* $K_{1}$ ( standart hata $\left.<\% 20\right) ; k_{x}($ standart hata $<\% 5)$ 


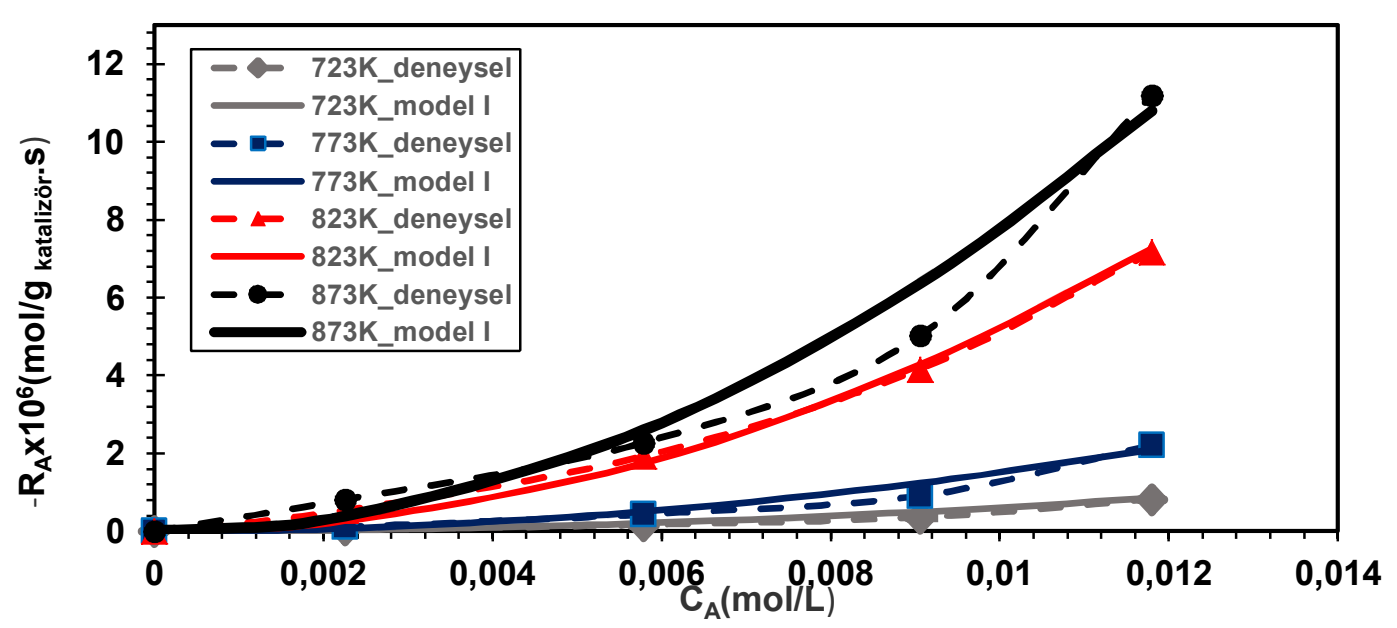

(a)

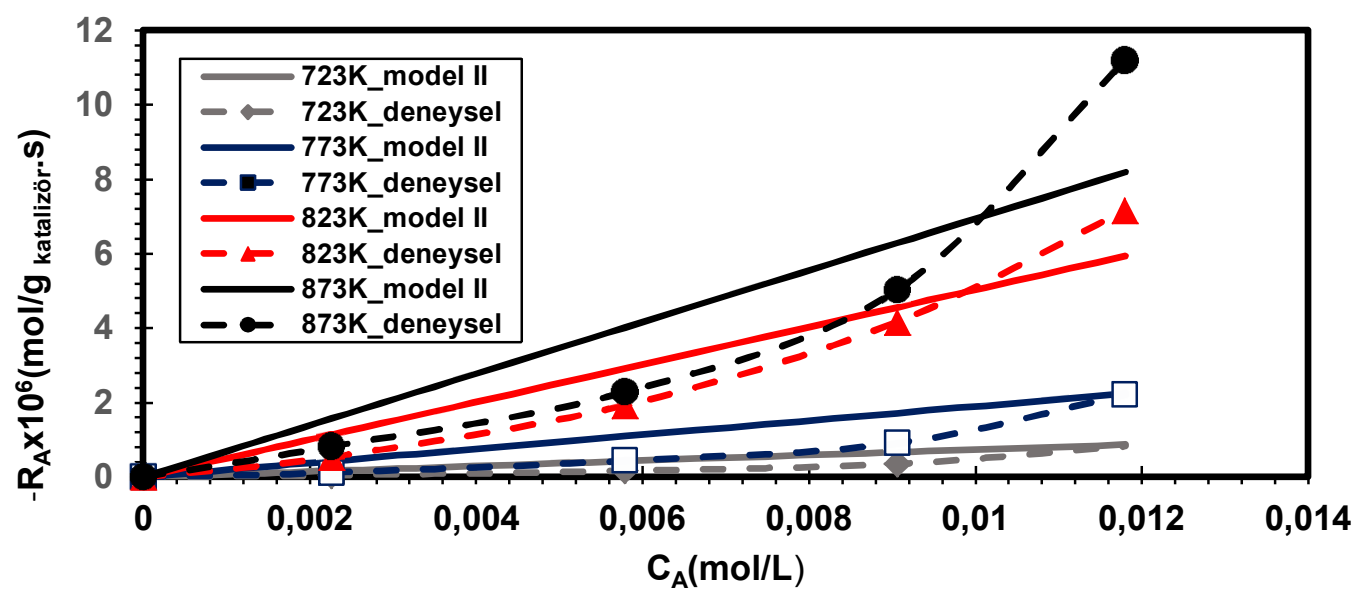

(b)

Şekil 2. Deneysel ve (a) Model I (b) Model II yaklaşımı ile belirlenen reaksiyon hızlarının konsantrasyon ile değişimi (Variation of reaction rates determined experimentally and with (a) Model I (b) Model II approach with concentration)

Hız sabiti değerleri, adsorpsiyon denge sabiti değerlerinden daha küçük mertebede belirlenmiştir. Model II' de belirlenen mertebe farkı Model I' de belirlenenin yaklaşık 10 katı büyüklüğünde tespit edilmiştir. Yüzey reaksiyonu basamağının reaksiyon hız ifadesinin belirlenmesinde önemli olduğu öngörüsünü desteklemiştir. Belirlenen adsorpsiyon denge sabiti değerleri ve hız sabiti değerleri literatür ile uyumlu bulunmuştur [6]. Elde edilen bu katsayılar ile her bir sıcaklık için farklı konsantrasyonlarda reaksiyon hızları hesaplanmıştır. Şekil 2' de deneysel ve Model I \& Model II yaklaşımı ile belirlenen reaksiyon hızlarının konsantrasyon ile değişimi verilmiştir. Şekil 2' den model ve deneysel reaksiyon hızlarının konsantrasyon ile arttığı görülmektedir. Model I' de bu artışın sıcaklık artışı ile daha belirgin bir hal aldığı tespit edilmiştir. Model I sonuçlarının deney sonuçları ile iyi uyum gösterdiği; Model II sonuçlarının ise deneysel sonuçlar ile uyumun iyi olmadığı tespit edilmiştir.

Deneysel ve Model I \& Model II yaklaşımına göre belirlenen reaksiyon hızlarının karşılaştırması Şekil 3' de verilmiştir. Çalışılan tüm sıcaklıklarda Model I için
$\mathrm{R}^{2}>0,95$; Model II için $\mathrm{R}^{2}<0,95$ olarak belirlenmiştir. $\mathrm{Bu}$ durum, Model I sonuçlarının deneysel reaksiyon hızı değerleri ile daha uyumlu olduğunu bir kez daha göstermiştir.

Eşitlik 7' deki Model I yaklaşımı ile belirlenen hız ifadesi için iki limit durum (Eş. 11-13) söz konusudur:

1.limit durum; $K_{1} \cdot C_{A}<<1$

$-R_{A}=k_{x} \cdot K_{1}^{2} \cdot C_{A}^{2}$

$-R_{A}=k_{y} \cdot C_{A}^{2} ; k_{y}=k_{x} \cdot K_{1}^{2}$

2.limit durum; $K_{1} \cdot C_{A}>>1$

$-R_{A}=k_{x}$

Eşitlik 9' da Model II yaklaşımı ile belirlenen hız ifadesi için de benzer şekilde iki limit durum (Eş. 1416) söz konusudur: 


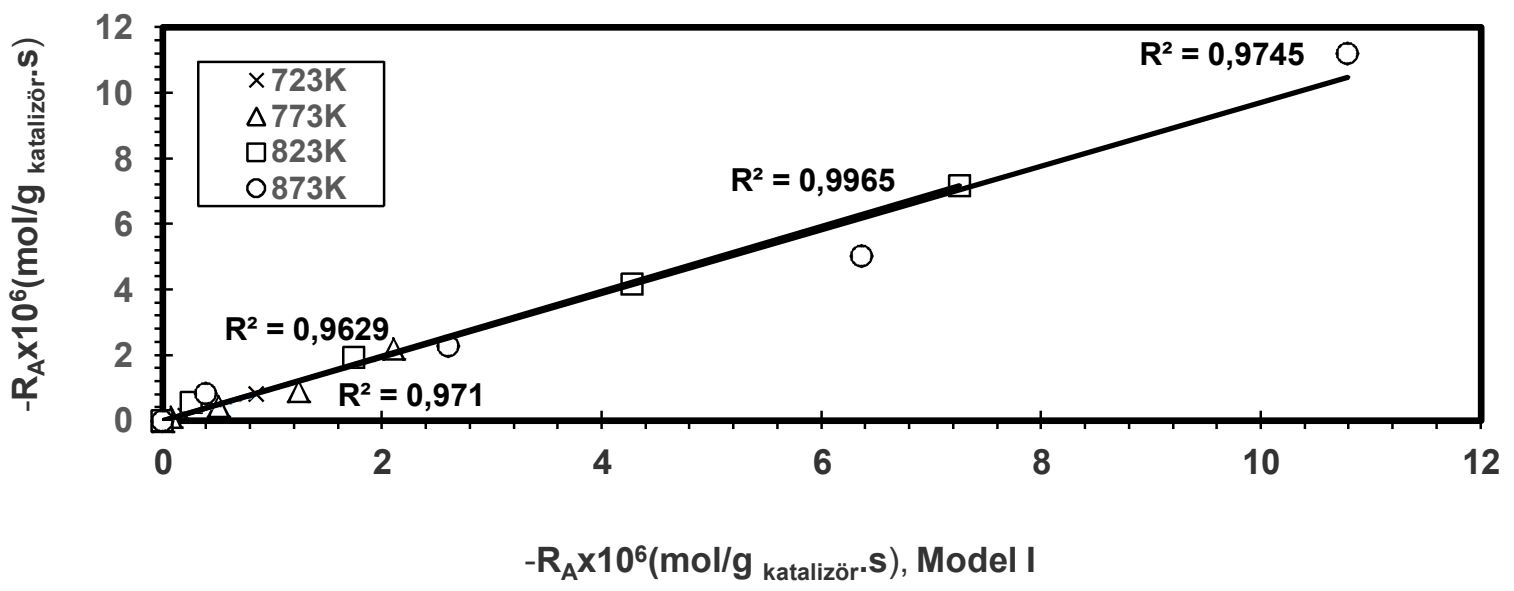

(a)

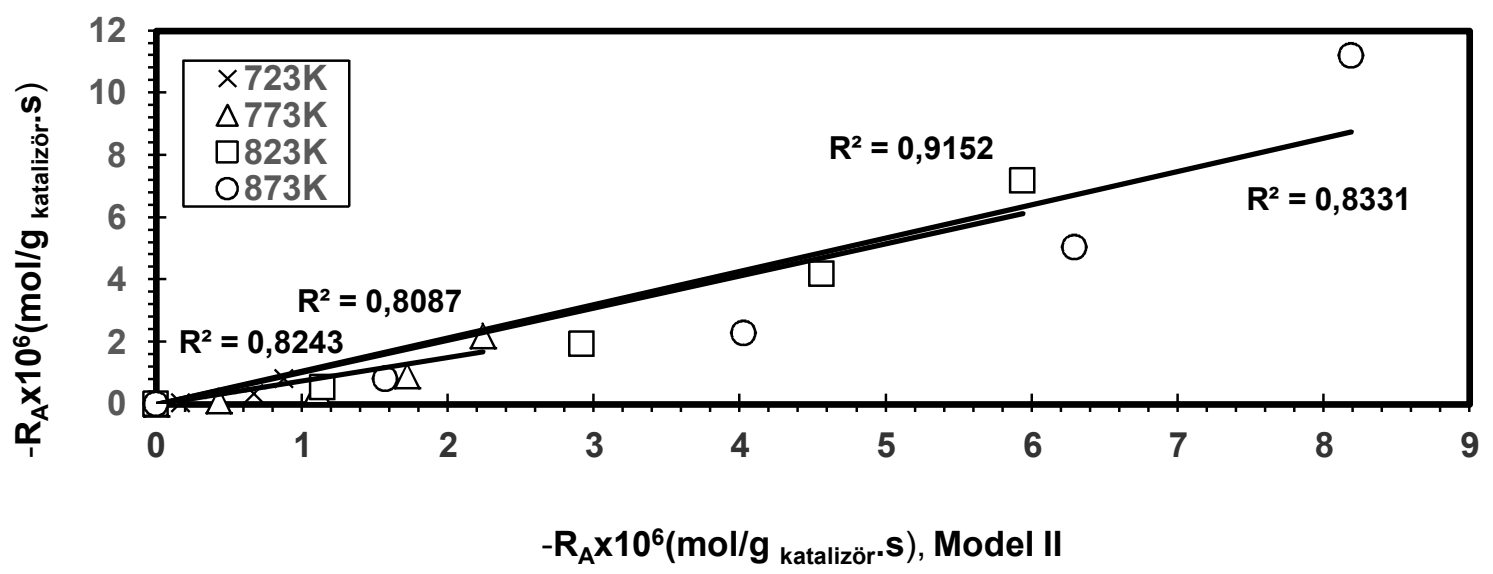

(b)

Şekil 3. Deneysel ve (a) Model I (b) Model II yaklaşımı ile belirlenen reaksiyon hızlarının karşılaştırması (Comparison of reaction rates determined experimentally and with (a) Model I (b) Model II approach)

1. limit durum; $K_{1} \cdot C_{A} \ll<1$

$-R_{A}=k_{z} \cdot K_{1} \cdot C_{A}$

$-R_{A}=k_{w} \cdot C_{A} ; k_{w}=k_{z} \cdot K_{1}$

2.limit durum; $K_{1} \cdot C_{A}>>1$

$-R_{A}=k_{z}$

Konsantrasyon ile $K_{l}, k_{x}, k_{z}$ sabitlerinin değerleri (Tablo 2) dikkate alındığında tüm sıcaklıklarda Model I ve Model II için birinci limit durumun $\left(K_{l} . C_{A}<<1\right)$ geçerli olduğu görülmektedir. Limit duruma göre hesaplanan reaksiyon hızı değerlerinin, model yaklaşımı ile belirlenen hız değerleri ile aynı olduğu belirlenmiş̧tir.
$\mathrm{Bu}$ durum, Sekil 2' de reaksiyon hılarının konsantrasyon ile değişiminin Model I yaklaşımı için lineer olmayan, Model II yaklaşımı için lineer olan bir davranış göstermesini açıklamıştır.

Model I ve Model II yaklaşımı ile farklı sıcaklıklarda belirlenen reaksiyon hiz sabiti değerlerinden yararlanılarak aktivasyon enerjisi elde edilmiştir. Arrhenius denklemine dayanarak Model I ve Model II için aktivasyon enerjisi sırasıyla, $50 \mathrm{~kJ} / \mathrm{mol} ; 58$ $\mathrm{kJ} / \mathrm{mol}$ olarak belirlenmiştir.

Deneysel olarak belirlenen aktivasyon enerjisi değeri, $55 \mathrm{~kJ} / \mathrm{mol}$ model sonuçları ile karşılaştıııldığında sonuçların birbiriyle uyumlu olduğu görülmektedir. Belirlenen aktivasyon enerjisi literatür ile de uyumludur [1, 6, 7]. Model I ve Model II yaklaşımı ile belirlenen adsorpsiyon denge sabitlerinin sicaklıkla değişimi Van' t Hoff eşitliği ile incelenmiş elde edilen grafik Şekil 4' de verilmiştir. 


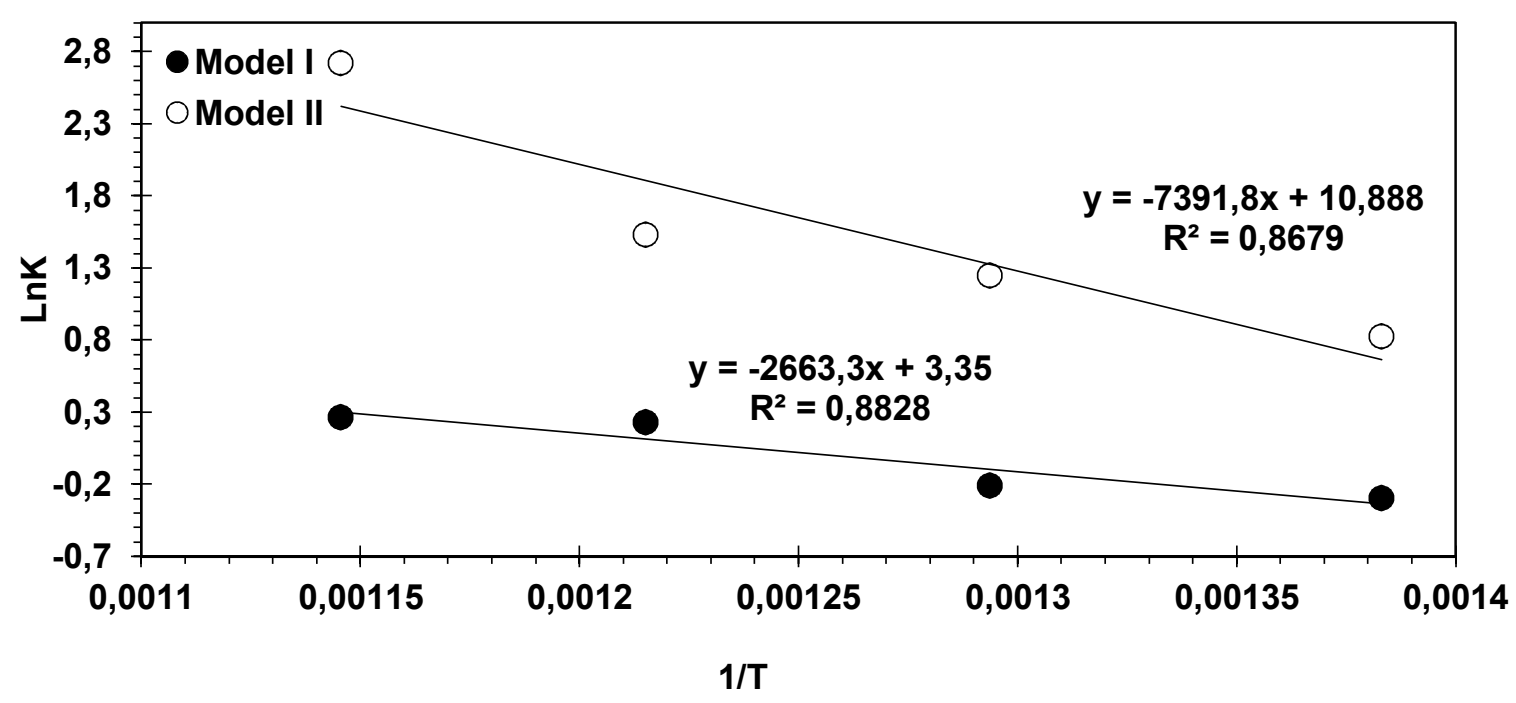

Şekil 4. LnK-1/T grafiği (LnK-1 / T graph)

Tablo 3. Model III yaklaşımına göre belirlenen parametreler* (Determined parameters based on Model III approach*)

\begin{tabular}{|c|c|c|}
\hline \multicolumn{3}{|c|}{ Model i } \\
\hline parametreler & $T=723 K$ & $T=873 K$ \\
\hline$k_{1}$ & 0,23 & $1,93 \times 10^{12}$ \\
\hline$k_{2}$ & $1,50 \times 10^{-7}$ & $1,50 \times 10^{-7}$ \\
\hline$\alpha$ & 2,81 & 7,54 \\
\hline$\beta$ & 2,83 & 4,00 \\
\hline$\gamma$ & 0,51 & 0,20 \\
\hline \multicolumn{3}{|c|}{ Model ii } \\
\hline parametreler & $T=723 K$ & $T=873 K$ \\
\hline$k_{1}$ & 0,23 & $4,20 \times 10^{9}$ \\
\hline$k_{2}$ & $1 \times 10^{-6}$ & $1 \times 10^{-11}$ \\
\hline$\alpha$ & 2,81 & 3,38 \\
\hline \multicolumn{3}{|c|}{ Model iii } \\
\hline parametreler & $\mathrm{T}=723 \mathrm{~K}$ & $T=873 K$ \\
\hline$k_{1}$ & $5,69 \times 10^{-5}$ & 0,001 \\
\hline$k_{2}$ & $2 \times 10^{-5}$ & $2 \times 10^{-5}$ \\
\hline$\beta$ & 2,00 & 5,00 \\
\hline \multicolumn{3}{|c|}{ Model iv } \\
\hline parametreler & $\mathrm{T}=723 \mathrm{~K}$ & $T=873 K$ \\
\hline$k_{1}$ & $5,69 \times 10^{-5}$ & 0,01 \\
\hline$k_{2}$ & 0,36 & 0,29 \\
\hline$\gamma$ & 5,55 & 28,87 \\
\hline \multicolumn{3}{|c|}{ Model v } \\
\hline parametreler & $\mathrm{T}=723 \mathrm{~K}$ & $T=873 K$ \\
\hline$k_{1}$ & $5,69 \times 10^{-5}$ & 0,001 \\
\hline$k_{2}$ & $1 \times 10^{-6}$ & $1 \times 10^{-9}$ \\
\hline
\end{tabular}

$* \mathrm{R}^{2}\left(\mathrm{R}^{2}=1\right.$-(artık karelerin toplamı/düzeltilmiş karelerin toplamı) $=0,750-0,986$ arasında değişim vermiş̧ir.

Grafiğin eğiminden adsorpsiyon entalpisi $(\Delta \mathrm{H})$ Model I ve Model II için sirasiyla $22 \mathrm{~kJ} / \mathrm{mol}$ ve $62 \mathrm{~kJ} / \mathrm{mol}$ olarak belirlenmiştir. Adsorpsiyon prosesinin her iki yaklaşım için endotermik olduğu görülmüştür.
Yüksek enerji gereksinimi katı yüzeyi ile adsorplanmış molekül arasında oluşan bağların sağlamlığının bir ölçüsüdür. Sıcaklık yükselmesiyle gözenekler açılmakta ve yüzeydeki aktif merkezler 
Tablo 4. Model III yaklaşımı ile belirlenen parametrelere göre hesaplanan reaksiyon hızı değerleri; mol/gat. $\mathrm{S}$ $\left(\mathrm{T}=723 \mathrm{~K} ; \mathrm{T}=873 \mathrm{~K}\right.$ ) (Calculated reaction rate values based on the parameters determined by Model III approach; mol $/ \mathrm{g}_{\text {kat. }} . \mathrm{s}$ $(\mathrm{T}=723 \mathrm{~K} ; \mathrm{T}=873 \mathrm{~K}))$

\begin{tabular}{|c|c|c|c|c|c|c|c|c|c|c|c|c|}
\hline \multirow[t]{2}{*}{$\mathrm{C}_{\mathrm{A} 0}$} & \multicolumn{2}{|c|}{$-\mathbf{R}_{\mathrm{A}} ;$ Model i } & \multicolumn{2}{|c|}{$-R_{A}$; Model ii } & \multicolumn{2}{|c|}{$-\mathbf{R}_{\mathrm{A}}$; Model iii } & \multicolumn{2}{|c|}{$-R_{A} ;$ Model iv } & \multicolumn{2}{|c|}{$-\mathbf{R}_{\mathrm{A}} ;$ Model v } & \multicolumn{2}{|c|}{$-R_{A}$; deneysel } \\
\hline & $723 K$ & $873 K$ & $723 K$ & $873 K$ & $723 K$ & $873 K$ & $723 K$ & $873 K$ & $723 K$ & $873 K$ & $723 K$ & $873 K$ \\
\hline 0,00226 & $8,29 \times 10^{-9}$ & $3,41 \times 10^{-10}$ & $8,29 \times 10^{-9}$ & 0,7353 & $1,28 \times 10^{-7}$ & $1,29 \times 10^{-6}$ & $1,28 \times 10^{-7}$ & $1,29 \times 10^{-5}$ & $1,28 \times 10^{-7}$ & $1,29 \times 10^{-6}$ & $4,53 \times 10^{-8}$ & $8,15 \times 10^{-7}$ \\
\hline 0,00579 & $1,17 \times 10^{-7}$ & $6,63 \times 10^{-7}$ & $1,17 \times 10^{-7}$ & 21,8795 & $3,29 \times 10^{-7}$ & $3,55 \times 10^{-6}$ & $3,29 \times 10^{-7}$ & $3,55 \times 10^{-5}$ & $3,29 \times 10^{-7}$ & $3,55 \times 10^{-6}$ & $1,74 \times 10^{-7}$ & $2,28 \times 10^{-6}$ \\
\hline 0,00906 & $4,10 \times 10^{-7}$ & $7,28 \times 10^{-6}$ & $4,10 \times 10^{-7}$ & 64,0745 & $5,14 \times 10^{-7}$ & $4,88 \times 10^{-6}$ & $5,14 \times 10^{-7}$ & $4,88 \times 10^{-5}$ & $5,14 \times 10^{-7}$ & $4,88 \times 10^{-6}$ & $3,62 \times 10^{-7}$ & $5,03 \times 10^{-6}$ \\
\hline 0,0118 & $8,62 \times 10^{-7}$ & $9,57 \times 10^{-6}$ & $8,62 \times 10^{-7}$ & 72,4691 & $6,69 \times 10^{-7}$ & $5,06 \times 10^{-6}$ & $6,69 \times 10^{-7}$ & $5,06 \times 10^{-5}$ & $6,69 \times 10^{-7}$ & $5,06 \times 10^{-6}$ & $8,77 \times 10^{-7}$ & $1,12 \times 10^{-5}$ \\
\hline
\end{tabular}

etkinleşmektedir [18]. Grafiğin kesim noktasından, entropi değişimi $(\Delta S)$ Model I ve Model II için sırası ile $0,007 \mathrm{~kJ} / \mathrm{mol}$ ve $0,09 \mathrm{~kJ} / \mathrm{mol}$ olarak elde edilmiştir. Entropi değişiminin pozitif olması adsorpsiyon proseslerinde genellikle beklenmemektedir, adsorpsiyon sonucunda düzensizlik azalmaktadır. Entropideki pozitif değerler, katı/gaz ara yüzeyindeki rastlantısallığın artışını ifade etmektedir [19]. Katalizör gözenek yapısı, biçimi, boyutu, kimyasal bileşimi v.b. özellikler katalizörde Van der Waals kuvvetlerinin oluşmasına neden olmaktadır. $\mathrm{Bu}$ kuvvetler, geçiş hallerinin stabilizasyonunu; adsorpsiyon/desorpsiyon dengesini ve yüzeyin kaplanmasını etkilemektedir. Katalizör yüzey alanı arttıkça, adsorplanma kapasitesi artmakta ve daha hızlı olarak adsorpsiyon meydana gelmektedir. Önceki makale çalışmamızda, MCM-41(yüzey alanı: $1250 \mathrm{~m}^{2} / \mathrm{g}$ ) yapısına kütlece $\% 3$ oranında hidrotermal olarak $\mathrm{Cr}$ ilavesinin yüzey alanını ciddi oranda $(\leq \% 20)$ düşürmediği, MCM-41 mezo gözenek yapısının korunduğu ve tek tip gözenek çap dağılım eğrisi (2nm) elde edildiği belirlenmiştir [15]. $\mathrm{Cr} / \mathrm{MCM}-41$ mezo gözenek yapısı ve yüksek yüzey alanı izobütan adsorpsiyon hızını artırarak reaksiyon hızını artırmış; mono ve bimoleküler reaksiyonların geçiş hallerinin stabilizasyonunu sağlamıştır. Üs yasası temel alınarak iki farklı sıcaklık için oluşturulan Model III yaklaşımına göre belirlenen parametreler Tablo 3' de verilmiştir. Tablo 3' den model denklemi değiştikçe ileri yöndeki reaksiyon hız sabiti $k_{l}$ ' nın sıcaklık değişimine bağlı olarak hassas değişim gösterdiği tespit edilmiştir. Model denkliği değişmiş olmasına rağmen $k_{1}$ değeri Model $i$ ve Model ii eşitlikleri için 0,23 değerinde; Model iii-v için $5,69 \times 10^{-5}$ değerinde bulunmuştur. Geri yöndeki reaksiyon hızı sabiti $k_{2}$ ' nin model i ve model iii için sabit kaldığ 1 , diğer modellerde ise sıcaklık arttıkça azalış gösterdiği tespit edilmiştir. Model III yaklaşımına göre indirgenmiş eşitlikler için belirlenen parametreler ile hesaplanan reaksiyon hızı değerleri Tablo 4 incelendiğinde, $723 \mathrm{~K}$ sicaklıkta Model i-ii; Model iii-iv için reaksiyon hız değerleri aynı bulunmuştur. $873 \mathrm{~K}$ sicaklıkta ise yalnızca Model iii ve Model v sonuçları aynı değerde hesaplanmıştır. Model ve deney sonuçları arasındaki en iyi uyum, 723K sıcaklıkta Model i ve Model ii denklemleri için belirlenmiş, ancak en düşük konsantrasyonda bu uyum gözlenmemiştir.

\section{TEŞEKKÜR (ACKNOWLEDGMENT)}

Sayın hocalarım Prof. Dr. Timur Doğu ve Doç. Dr. Meltem Doğan' a teşekkür ederim.

\section{SONUÇLAR (CONCLUSIONS)}

İzobütan dehidrojenasyonun $\mathrm{Cr} / \mathrm{MCM}-41$ katalizörü üzerindeki reaksiyon mekanizması belirlenmeye çalışılmıştır. Mekanizma çalışmaları, yüzey reaksiyonunun kontrolünü temel alan mono ve bimoleküler reaksiyonlar (Model I \& Model II) ve üs yasası kuralı (Model III) temel alınarak yürütülmüştür. Model çalışmalarına ait parametreler SPSS 17.0 programından yararlanılarak regresyon analizleri ile gerçekleştirilmiştir. Model çalışmalarından deney sonuçları ile en iyi uyum, çok karmaşık mekanizma çalışmalarına gereksinim duyulmadan bimoleküler yüzey reaksiyonu kontrollü mekanizmaya dayanan Model I yaklaşımında tespit edilmiştir. Cr/MCM-41 katalizörü üzerinde izobütan dehidrojenasyonu reaksiyonuna ait herhangi bir hiz ifadesi ve mekanizma çalışmasının olmadığı dikkate alındığında, çalışmanın bu yöndeki çalışmalara katkı sağlayacağı düşünülmektedir.

\section{KAYNAKLAR (REFERENCES)}

1. Sahebdelfar, S., Moghimpour Bijani, P., Saeedizad, M., Tahriri Zangeneh, F. and Ganji, $\mathrm{K}$., "Modeling of adiabatic moving-bed reactor for dehydrogenation of isobutane to isobutene", Applied Catalysis A: General, Cilt 395, 107113, 2011.

2. Fang, D., Zhao, J., Liu, S., Zhang, L., Ren, W. and Zhang, H., "Relationship between $\mathrm{Cr}-\mathrm{Al}$ 
Interaction and the Performance of $\mathrm{Cr}-\mathrm{Al}_{2} \mathrm{O}_{3}$ Catalysts for Isobutane Dehydrogenation", Modern Research in Catalysis, Cilt 4, 50-58, 2015.

3. Fang, D., Zhao, J., Li, W., Fang, X., Yang, X., Ren, W. and Zhang, H., "Investigation of the characteristics and deactivation of catalytic active center of $\mathrm{Cr}-\mathrm{Al}_{2} \mathrm{O}_{3}$ catalysts for isobutane dehydrogenation", Journal of Energy Chemistry, Cilt 24, 101-107, 2015.

4. Zhao, H., Song, H., Miao, Z. and Chou, L., "Isobutane dehydrogenation over chromia alumina catalysts prepared from MIL-101: Insight into chromium species on activity and selectivity", Journal of Energy Chemistry, Cilt 23, No 6, 708-716, 2014.

5. Sattler, J.J.H.B., Ruiz-Martinez, J., SantillanJimenez, E. and Weckhuysen, B.M., "Catalytic Dehydrogenation of Light Alkanes on Metals and Metal Oxides", Chem. Rev., Cilt 114, 10613-10653, 2014.

6. Casanave, D.K., Fiaty, J.A. and Dalmon, M., "Kinetics and mechanism studies of the catalytic dehydrogenation of isobutane on PlatinumIndium catalyst", Reaction Kinetics and the Development of Catalytic Processes, 367-374, 1999.

7. Minh, Cam Le and Brown, T.C., "Rate parameters from low-pressure steady-state protolytic cracking and dehydrogenation of isobutane over zeolite catalysts", Applied Catalysis A: General, Cilt 310, 145-154, 2006.

8. Yanping, S. and Trevor, C.B., "Kinetics of isobutane dehydrogenation and cracking over HZSM-5 at low pressures", Journal of Catalysis, Cilt 194, 301-308, 2000.

9. Milas, I. and Nascimento, M.A.C., "The dehydrogenation and cracking reactions of isobutane over the ZSM-5 zeolite", Chemical Physics Letters, Cilt 373, 379-384, 2003.

10. Sanchez-Castillo, M.A., Agarwal, N., Bartsch, A., Cortright, R.D., Madon, R.J. and Dumesic, J.A., "Reaction kinetics studies and analyses of isobutane conversion over $\mathrm{H}$-mordenite and $\beta$ zeolite", Journal of Catalysis, Cilt 218, 88-103, 2003.
11. Bijani, P. M., and Sahebdelfar, S., "Modeling of a Radial-Flow Moving-Bed Reactor for Dehydrogenation of Isobutane", Kinetics and Catalysis, Cilt 49, 4, 599-605, 2008.

12. Rashidi, M., Nikazar, M., Rahmani, M. and Mohamadghasemi, Z., "Kinetic modeling of simultaneous dehydrogenation of propane and isobutane on Pt-Sn-K/ $/ \mathrm{Al}_{2} \mathrm{O}_{3}$ catalyst", Chemical Engineering Research and Design, Cilt 95, 239-247, 2015.

13. Vernikovskaya, N.V., Savin, I.G., Kashkin, V.N., Pakhomova, N.A., Ermakova, A., Molchanov, V.V., Nemykina, E.I. and Parahin, O.A. "Dehydrogenation of propane-isobutane mixture in a fluidized bed reactor over $\mathrm{Cr}_{2} \mathrm{O}_{3} / \mathrm{Al}_{2} \mathrm{O}_{3}$ catalyst: Experimental studies and mathematical modelling", Chemical Engineering Journal, Cilt 176- 177 158-164, 2011.

14. Miracca, I. and Piovesan, L., "Light paraffins dehydrogenation in a fuidized bed reactor", Catalysis Today, Cilt 52, 259-269, 1999.

15. Kilicarslan, S., Dogan, M. and Dogu, T., "Cr Incorporated MCM-41 Type Catalysts for Isobutane Dehydrogenation and Deactivation Mechanism", Ind. Eng. Chem. Res., Cilt 52, 3674-3682, 2013.

16. Piccolo, L. and Henry, C.R., "Reactivity of metal nanoclusters: nitric oxide adsorption and $\mathrm{CO}+\mathrm{NO}$ reaction on $\mathrm{Pd} / \mathrm{MgO}$ model catalysts", Applied Surface Science, 162-163, 670-678, 2000.

17. Lee, S.B., Shin, H. S. and Ryu, D.D.Y., “ Adsorption of Cellulase on Cellulose: Effect of Physicochemical Properties of Cellulose on Adsorption and Rate of Hydrolysis", Biotechnology and Bioengineering, DOI: 10.1002/bit.260241003, 2015.

18. Mahramanlıoğlu, M., Kızılcıklı, İ., Ustaer, C., Tuncay, M., "Aktifleştirilmiş Bentonit Kullanarak Sulu Çözeltilerden Boyar Madde Uzaklaştırılması", Mühendislik Bilimleri Dergisi, Cilt 10, 2, 151-156, 2004.

19. Kayacan, S., "Kömür Ve Koklarla Sulu Çözeltilerden Boyar Maddelerin Uzaklaştırılması”, Yüksek Lisans Tezi, Ankara Üniversitesi Kimya Anabilim Dalı, 2007. 
